\title{
Экологические проблемы Байкала
}

В.И. ЗОРКАЛЬЦЕВ, Доктор теХНИческих Наук, ИНститут сИстем энергетики им. Л. А. Мелентьева СО РАН, Иркутский научный центр СО РАН, Отдел региональных экономических и социальных проблем (ОРЭСП).

E-mail: zork@isem.irk.ru

А.Н. КУЗНЕЦОВА, кандидат эКОНомических наук, ИНЦ СО РАН, ОРЭСП. E-mail: an@isc.irk.ru

Н.M. СЫСОЕВА, доктор географических наук, ИНЦ СО РАН, ОРЭСП, Институт географии имени В.Б. Сочавы СО РАН, Иркутский государственный университет, Иркутск. E-mail: syssoeva@oresp.irk.ru

Рассматриваются экологические проблемы Байкальской природной территории, имеющиеся трудности их решения. Многие проблемы проистекают из-за территориальной и ведомственной разобщенности органов власти, занимающихся организацией функционирования и развития единой Байкальской природной территории. Обсуждается возможность использования организационного опыта возрождения Великих озер Северной Америки. Особое внимание уделяется необходимости развития научных исследований Байкала' ${ }^{1}$.

Ключевые слова: экологические проблемы, Байкальская природная территория, экосистема озера Байкал

Байкал издавна является ареалом расселения людей, их производственной деятельности. И нередко - в ущерб природной чистоте озера. Наиболее ощутимо это стало в период индустриального развития Байкальской территории, особенно в последние десятилетия, в результате развития туризма и неорганизованного отдыха на Байкале. Пришло время для перехода к стратегии рациональной организации жизнедеятельности и отдыха на Байкале, при которой разумно сочетались бы задачи экономического развития Байкальской территории и сохранения Байкала [Грачев, 2002].

\section{Истоки экологических проблем Байкала}

Озеро Байкал - самый большой по площади объект всемирного природного наследия ЮНЕСКО. Площадь акватории озера 31,5 тыс. км ${ }^{2}$ - примерно поровну поделена между Иркутской областью и Республикой Бурятия. С учетом жестких экологических требований мирового и российского законодательства к сохранению мирового природного наследия, для субъектов

\footnotetext{
${ }^{1}$ Исследования выполняются при финансовой поддержке РФФИ и Правительства Иркутской области, грант № 17-410-380003.
} 
Российской Федерации Байкальского региона (Иркутская область, Республика Бурятия, Забайкальский край) особенно важно установить разумные экологические правила хозяйственной и рекреационной деятельности на Байкале.

В 1999 г. в Российской Федерации был принят федеральный закон «Об охране озера Байкал»². В данном законе была выделена Байкальская природная территория (БПТ) для соблюдения особой экологической политики, нацеленной на охрану и сбережение уникального природного объекта. На территории БПТ законом выделены три экологические зоны: центральная, буферная, атмосферного влияния. Наиболее жесткие экологические ограничения на природопользование установлены для центральной экологической зоны, включающей акваторию озера, водоохранную зону побережья и прилегающие к нему особо охраняемые природные территории ${ }^{3}$.

Проблемы Байкала являются лакмусовой бумажкой экологической политики государства. Само общественное экологическое движение в России, осознанная представителями науки и органов власти необходимость учета экологических ограничений зародились в нашей стране именно в период планирования строительства Байкальского целлюлозно-бумажного комбината (БЦБК). В 1958 г. на Всесоюзной конференции по развитию производительных сил Восточной Сибири некоторые ее участники выступили против реализации проекта «Гипробума» о размещении на берегу Байкала комбината [Суходолов, 1996].

Построенный Байкальский комбинат долго оставался главным загрязнителем озера. В 2013 г. он наконец-то был закрыт. Остались только порожденные им проблемы, в частности, с теплоснабжением города Байкальска, поскольку изначально оно осуществлялось с ТЭЦ при этом комбинате. Как источник теплоснабжения только города ТЭЦ неэффективна.

Вторая проблема - огромные запасы отходов производства, накопившиеся за много лет функционирования комбината. Около

${ }^{2}$ Федеральный закон от 01.05.1999 г. № 94-Ф3 «Об охране озера Байкал» // Собрание законодательства РФ, 03.05.1999. № 18, ст. 2220.

Постановление Правительства РФ от 30.08.2001 г. № 643 «Об утверждении перечня видов деятельности, запрещенных в центральной экологической зоне Байкальской природной территории (с изменениями на 2 марта 2015 года) [Эл. pecypc]. URL: http://ocs. cntd.ru/document/901795935 (дата обращения: 20.11.2017).
200 га берега озера заняты шлам-отстойниками и картами-накопителями, в которых находится около 6,2 млн т шлам-лигнина и 2,8 млн т золы. Эти загрязняющие вещества вместе подземными и паводковыми водами попадают в Байкал. Исследования Росгидромета в 100-метровом створе выпуска комбината до сих пор регулярно фиксируют превышение веществ, специфических для целлюлозной промышленности. Существует и реальная угроза разрушения накопителей отходов, загрязнение озера в результате селей и землетрясений, которые здесь нередки.

К сожалению, многолетняя история Байкальского ЦБК не привела к созданию эффективных механизмов решения экологических и экономических проблем Байкальской природной территории. В частности, не решена проблема утилизации жидких и твердых бытовых отходов населенных пунктов и туристических баз на берегу Байкала.

На расширенном заседании Общественного совета при Минприроды России (31.01.2017), посвященном проблемам Байкала, министр природных ресурсов и экологии РФ С.Е. Донской отметил: «Сегодня главный фактор загрязнения Байкала, возможно, и причина эвтрофикации озера - это сточные воды, это сбросы системы ЖКХ» ${ }^{4}$. Состояние жилищно-коммунального хозяйства Байкальской природной территории, в первую очередь, в центральной экологической зоне характеризуется крайней изношенностью большинства объектов коммунальной инфраструктуры, низкой эффективностью очистки сточных вод.

Очевидно, что первоочередной задачей является строительство новых, а также реконструкция и модернизация старых очистных сооружений. Всего Минприроды планирует профинансировать строительство и модернизацию 46 очистных комплексов на сумму около 11 млрд руб. В 2014-2016 гг. работа велась на восьми объектах (введены в эксплуатацию только два, хотя израсходовано более 3,5 млрд руб.). Но, по признанию специалистов, модернизация не улучшила качество очистки, что свидетельствует о низкой эффективности проделанной работы. В 2017 г. началась реконструкция комплекса очистных сооружений в г. Улан-Удэ-

${ }^{4}$ Донской C. Е. Бурятия, Иркутская область и Забайкальский край в 2017 г. перейдут на новую систему управления в сфере обращения с отходами [Эл. ресурc]. URL: http://www.mnr.ru./news/detail.php? ID=341922\& sphrase_id=3999256 (дата обращения: 10.11.2017). 
одном из крупнейших загрязнителей озера через приток Байкала Селенгу (50\% стока всех рек бассейна озера). Важно обеспечить надлежащую экспертизу и надзор за реализацией этого проекта.

Около $80 \%$ экологических правонарушений, допущенных хозяйствующими субъектами, работающими в границах БПТ, связано с невыполнением требований законодательства в области использования и охраны водных объектов и обращения с отходами 5 . В Бурятии ежегодно образуется в среднем свыше 50 млн т отходов производства и потребления, в том числе 275,6 тыс. т твердых коммунальных отходов. В Иркутской области - около 120 млн т отходов; из них около 96\% приходится на добычу полезных ископаемых (в основном вскрышные породы горнодобывающей промышленности) $)^{6}$.

Согласно федеральному закону об отходах производства и потребления в субъектах Федерации разработаны и утверждены территориальные схемы обращения с отходами, на которых должна быть основана деятельность региональных операторов - бизнес-структур, ответственных за координацию всех мероприятий по транспортировке и утилизации бытового мусора и отходов производства 7 . Территориальные схемы должны сопровождаться разработкой региональных программ, которые, в свою очередь, позволят создать инфраструктуру по обращению с отходами, ориентированную на вовлечение их в хозяйственный оборот.

Однако региональные особенности, связанные с экологическими ограничениями хозяйственной деятельности, стали причиной трудностей при формировании территориальных схем обращения с отходами. Так, в Иркутской области территориальная схема была утверждена в декабре 2016 г., а уже в июне следующего года приказ об утверждении схемы был отменен решением Иркутского областного суда. Находясь длительное

5 Донской С. Е. В результате проверки Байкальской природной территории выявлено 527 нарушений, ущерб природе составил 130 млн рублей. [Эл. pecypc]. URL: http://www. mnr.gov.ru/news/detail.php? ID=344237 (дата обращения: 02.02.2018).

${ }^{6}$ Пионко E. Мусор: от сбора до утилизации // Областная газета (Иркутская обл.). 2017. № 27 (1637). С. 4

7 Федеральный закон от 29.12.2014 № 458-Ф3 (ред. от 28.12.2016) «О внесении изменений в Федеральный закон “Об отходах производства и потребления", отдельные законодательные акты Российской Федерации и признании утратившими силу отдельных законодательных актов (положений законодательных актов) Российской Федерации» [Эл. pecypc]. URL: http://www.consultant.ru/document/cons_doc_LAW_172948/ (дата обращения: 20.09.2017) время в процессе корректировок и согласований, документ так и не был утвержден в 2017 году8

В Республике Бурятия также отмечаются серьезные экономические и социальные проблемы реализации территориальной схемы ${ }^{9}$. Одной из проблем, сдерживающих развитие инфраструктуры обращения с отходами, является совпадение границ водоохранной зоны озера Байкал и центральной экологической зоны. Запрет на размещение мест захоронения отходов производства и потребления требует переноса данных объектов за пределы водоохранной зоны (в прибрежных районах - это 65-150 км), что влечет увеличение стоимости вывоза отходов. Ожидается, что жителям придется платить не только за вывоз, но и за переработку отходов. При низкой платежеспособности это будет приводить к банкротству организаций, осуществляющих вывоз отходов и, в конечном итоге, к загрязнению прилегающих к озеру Байкал территорий. В целом программа «мусорной реформы» оценивается республикой в 14 млрд руб. ${ }^{10}$

В связи с заметным увеличением числа судов на Байкале следует упомянуть и о необходимости формирования современной инфраструктуры, обслуживающей суда на побережье. А также - о формировании унифицированных, строгих и при этом разумных требований к судоходству, позволяющих, в частности, сделать водные путешествия по Байкалу более доступными для широких слоев населения.

На сегодняшний день жесткие экологические ограничения, особенно в центральной экологической зоне БПТ, противоречат интересам местного населения, так как сдерживают развитие производства и инфраструктуры региона, отрицательно влияют на количественные и качественные параметры занятости трудовых ресурсов. Так, большое социальное напряжение вызывает введенный с 01.10.2017 г. запрет на промышленный лов омуля,

${ }^{8}$ Территориальную схему обращения с отходами в Иркутской области доработают к ноябрю [Эл. pecypc]. URL: https://www.irk.ru/news/20170918/scheme/ (дата обращения 21.10.2017).

${ }^{9}$ Иващенко T. «Мусорная» проблема в Бурятии упирается в Байкал [Эл. ресурс] URL: https://regnum.ru/news/2203484.html (дата обращения: 17.11.2017);

${ }^{10}$ Иванов A. Большая «мусорная реформа» обойдётся Бурятии в 14 млрд рублей. [Эл. pecypc]. URL: https://regnum.ru/news/2203484.html (дата обращения: 15.11.2017). 
который для многих жителей Байкала составлял основной источник заработка ${ }^{11}$.

\section{Трудные пути решения экологических проблем}

В качестве основного инструмента решения байкальских проблем предполагалась Федеральная целевая программа «Охрана озера Байкал и социально-экономическое развитие Байкальской природной территории на 2012-2020 годы» (ФЦП «Байкал»), утвержденная в 2012 г. ${ }^{12}$ (государственный заказчик, координатор Программы - Министерство природных ресурсов и экологии РФ). Отсутствие комплексного системного анализа предлагаемых инновационных производств и мероприятий во многом стало причиной крайне неудовлетворительной (практически провальной) реализации ФЦП «Байкал». За 2012-2016 гг. на различные природоохранные мероприятия на БПТ было выделено около 10 млрд руб. (гораздо меньше, чем предусматривалось). Однако многие из предложенных в ФЦП мер не оказывали непосредственного влияния на состояние озера.

Предложения Академии наук РФ начать программу с научных исследований и выработки рекомендаций по устранению основных проблем БПТ были отвергнуты. В результате сложилась парадоксальная ситуация - объемы финансирования в государственной программе запланированы, но получить их на строительство конкретных объектов невозможно: проектносметная документация либо отсутствовала вообще в первые годы реализации программы, либо не прошла все уровни государственной экспертизы. Кураторы ФЦП обвиняют во всем регионы, которым, как правило, неоткуда было получить средства на проекты. Из-за ошибок в управлении ФЦП «Байкал» ряд первоочередных мероприятий не был выполнен, средства не осваивались своевременно, проблемы Байкала усугублялись. Частые корректировки программы, ее сокращение с 58

\footnotetext{
${ }^{11}$ Шагунова Л. Сушим сети, сматываем удочки... Минсельхоз России запретил вылов омуля на Байкале // Областная газета (Иркутская обл.). 2017. № 111 (1721). С. 6.

${ }^{12}$ Федеральная целевая программа «Охрана озера Байкал и социально-экономическое развитие Байкальской природной территории на 2012-2020 годы». Утв. постановлением Правительства РФ от 21.08.2012 г. № 847 [Эл. pecypc]. URL: https://legalacts.ru (дата обращения: 15.11.2017).
}

до 26 млрд руб., вызывали нарекания Минэкономразвития РФ, вплоть до выступлений с инициативой досрочно закрыть ФЦП.

В целевых индикаторах ФЦП планировалось «существенное сокращение поступления в акваторию озера Байкал загрязненных сточных вод - до 68,4\% к 2020 г. по сравнению с 2010 г.; реабилитация $80 \%$ Байкальской природной территории, подвергшейся высокому и экстремально высокому загрязнению».

Согласно данным Государственного доклада о состоянии озера Байкал и мерах по его охране в 2015 г. ${ }^{13}$, объемы сбросов в поверхностные водные объекты составляли в целом по БПТ: в 2008 г. $-527,0$ млн м³; в 2010 г. $-422,0$; в 2015 г. $-507,1$ млн м ${ }^{3}$. Выбросы от стационарных источников: в 2008 г. - 520,0 тыс. т; в 2010 г. $-434,2$; в 2015 г. $-426,6$ тыс. т. Образование отходов (тыс. т): в 2010 г. $-31071,0$ тыс. т; в 2015 г. $-111499,0$ тыс. т. (в основном, за счет роста объемов производственных отходов). Можно отметить некоторое снижение в последние годы показателей антропогенной нагрузки по сбросам и выбросам в центральной экологической зоне БПТ, но при этом образование отходов возросло с 531 тыс. т в 2010 г. до 889,8 тыс. т в 2015 г.

Факт загрязнения озера Байкал сточными водами с повышенным содержанием фосфора и азота подтверждается данными проверок Росприроднадзора. К счастью, результаты экологического мониторинга озера Байкал и комплексной оценки его состояния свидетельствуют, что до настоящего времени антропогенное влияние не привело к значимым изменениям гидрохимического режима в масштабе всего озера.

Начато решение проблемы ликвидации производственных отходов БЦБК. В конце 2017 г. имущество комбината как частной собственности кредиторов было передано в государственную собственность Иркутской области, что позволяет начать работу по ликвидации отходов. Сроки реализации работ по ликвидации отходов - 2017-2020 гг; стоимость реализации - около 6 млрд руб. Тогда же Правительство РФ назначило акционерное общество «Росгеология» единственным подрядчиком для работ по преобразованию и утилизации шлам-лигнина. Ранее рассматриваемые технологии утилизации (омоноличивание,

${ }^{13}$ Государственный доклад о состоянии озера Байкал и мерах по его охране в 2015 году. Министерство природных ресурсов и экологии Российской Федерации, 2016. 
термолиз) некоторые специалисты считают экологически неприемлемыми ${ }^{14}$. Подрядчик представил свой проект утилизации, к которому у экологов тоже есть много вопросов. К сожалению, не рассматривается более дешевое решение Лимнологического института СО РАН, предлагающего технологию перемешивания шлама и золы с получением в итоге почвогрунта, на котором могут расти трава и деревья.

Год 2017-й был объявлен годом перехода субъектов Федерации Байкальского региона на новую систему управления отходами. Но реализацию нового порядка обращения с отходами тормозят проблемы взаимодействия органов власти федерального и регионального уровней ${ }^{15}$. К тому же все полномочия по сбору, транспортировке и утилизации твёрдых коммунальных отходов возложены на регионы. Муниципальные власти не могут контролировать работу региональных операторов на своей территории. Необходимость комплексного решения проблем сбора и утилизации мусора потребовала разработки дополнительного регионального законодательства.

Очевиден вывод и о необходимости объединения усилий субъектов Байкальского региона для решения общей проблемы сохранения экологической системы Байкала путем согласования своих территориальных схем и региональных нормативных актов. Это подтвердили участники совещания Межправительственной рабочей группы по вопросам развития Байкальской природной территории и Межфракционной рабочей группы «Байкал» 20 ноября 2017 г. в Улан-Удэ ${ }^{16}$. Но создание межрегиональных территориальных схем не предусмотрено федеральным законодательством, и для совместной работы регионов пока нет правовой основы. Не апробированы и новые правила обращения с твердыми коммунальными отходами, регламентированные постановлением Правительства РФ от 12.11.2016 г. № 1156. Именно

${ }^{14}$ Колганов А. Затаившийся монстр БЦБК [Эл. pecypc]. URL: baikal.mk.ru (дата обращения: 27.11.2017)

${ }^{15}$ Юрков А. Долг по-байкальски. Бюрократическая кутерьма мешает реальной помощи озеру Байкал //Российская газета-Федеральный выпуск № 7371 (205).

${ }^{16}$ Материалы совместного заседания Межправительственной рабочей группь по вопросам развития Байкальской природной территории и Межфракционной рабочей группы «Байкал» 20.11.2017 г., г. Улан-Удэ [Эл. pecypc]. URL: http://minprirodarb.ru/ mrg-baykal (дата обращения: 21.11.2017). этот документ призван регулировать систему расчета операторов с подрядчиками и другие немаловажные аспекты.

Общей проблемой для всех регионов является то, что узаконенная обязательная переработка полезных компонентов отходов должна опираться на сформированную систему потребления продуктов переработки, которую еще необходимо создать.

Так как подавляющую долю отходов региона составляют производственные, то на федеральном уровне целесообразно разработать отдельный нормативно-правовой акт, регламентирующий обращение с производственными отходами добывающих предприятий и перерабатывающих производств. Этот документ должен стать основой для управления отходами в процессе разведки, извлечения, обработки и хранения полезных ископаемых и при работах на карьерах, выделяя их из общей массы отходов добывающих предприятий.

\section{Проблемы управления природоохранной деятельностью: опыт восстановления Великих озер}

Ход реализации ФЦП «Байкал» показывает, что организационно-правовой механизм управления устойчивым развитием таких сложных экологических систем, как Байкальская природная территория, требует корректировки в двух направлениях. Во-первых, управление Байкальской природной территорией, расположенной в нескольких субъектах Федерации, не может ограничиться компетенциями и действиями одного профильного министерства. Комплексные и достаточно оперативные решения экологических проблем для крупнейших природных систем требуют межрегионального и надведомственного по статусу правительственного органа (комитета), с большими правами, позволяющими реализовать решения с федеральными министерствами и субъектами Федерации.

Во-вторых, обычные подходы к решению задач через финансирование программ крупных проектов не позволяют реализовать мероприятия малого масштаба, рассеянные по территории, к которым относится ликвидация воздействия сбросов и выбросов жилищно-бытового сектора и мелких производств, особенно в центральной экологической зоне. Вовлечение в процесс экологического оздоровления местных жителей, общественных 
организаций, волонтеров и других представителей гражданского общества, научной и образовательной сфер требует расширения и дополнения механизмов распределения средств и ответственности между множеством реальных и потенциальных субъектов экологической политики на территории.

Человечество накопило определенный опыт организации работ по сохранению речных и озерных экосистем, расположенных в нескольких административных образованиях или странах. Сравнимой с задачей развития Байкальской природной территории является программа восстановления Великих озер в Северной Америке, осуществляемая совместно США и Канадой и потребовавшая организации сотрудничества на региональном, национальном и международном уровнях.

Межгосударственное взаимодействие по Великим озерам началось еще в 1909 г. и имеет богатую историю, но функционирующая в настоящее время система управления охраной и восстановлением Великих озер в Соединенных Штатах сложилась, в основном, в последние полтора десятилетия. В настоящее время систему федеральных и штатских мероприятий формирует так называемая Инициатива по восстановлению Великих озер, принятая в 2010 г. Агентство по охране окружающей среды (ЕРА) является федеральным уполномоченным агентством по выполнению и администрированию Инициативы. Оно получает и распределяет утвержденные конгрессом средства среди нескольких федеральных агентств, которые осуществляют мероприятия по проектам. Координирует федеральные усилия по восстановлению экосистемы Великих озер Межведомственный комитет, созданный в 2004 г. для реализации Стратегии регионального сотрудничества по восстановлению озерных экосистем. В реализации Инициативы участвует также Консультативный совет из представителей нефедеральных субъектов Инициативы (неправительственные организации, штатские агентства, племена, университеты и т.д.) [Albert M. T. at al; Great Lakes..,2010]. В 2015 г. был запущен План действий-2 Инициативы до 2019 г., призванный выйти на новую стадию решения экологических задач в регионе, в том числе связанную со здоровьем населения [Great Lakes..,2014].

Выполнение Инициативы осуществляется через План действий Комитета, в рамках которого каждый год федеральные агентства определяют проекты для реализации. Среди критериев для выбора: возможность быстрого выполнения, получение измеряемых или осязаемых результатов, соблюдение принципа наилучших доступных технологий, общественная поддержка проекта, низкие трансакционные издержки и привлечение нефедеральных ресурсов. Проекты направлены на достижение как общих, так и промежуточных целей и задач, которые сопровождаются количественными индикаторами. Получатели средств должны представлять отчеты по проектам и показывать прогресс по отношению к промежуточным целям и задачам Плана действий. Агентство собирает отчеты и составляет ежегодный доклад президенту по мероприятиям и результатам. С начала 2010 г. до конца февраля 2018 г. в рамках Инициативы было профинансировано 3956 проектов на общую сумму 2,1 млрд долл. [GLRI Projects].

Сейчас озера полностью избавлены от неочищенных промышленных и муниципальных стоков, существенно улучшилось качество воды, восстановлена ихтиофауна.

В Канаде вопросы охраны среды - предмет совместного ведения федерации и провинций, поэтому аналогом Стратегии регионального сотрудничества по восстановлению Великих озер является Соглашение Канада - Онтарио, на основе которого формируются планы действий как федерального, так и региональных агентств по охране окружающей среды [Evaluation..,2017].

\section{Российские реалии: комиссия есть, статуса нет}

Многолетний опыт формирования институциональной структуры, обеспечивающей восстановление целостной экосистемы Великих озер, подтверждает необходимость использования для природосбережения таких базовых положений, как единый центр координации и управления, комплексность, планомерность, программно-целевой подход, перманентность, легитимность, обязательность мониторинга и отчетности, активное привлечение науки и общественности.

В 2007 г. приказом Минприроды РФ была создана специальная Межведомственная комиссия по вопросам охраны озера Байкал. В первом пункте Положения об этой комиссии сказано ${ }^{17}$,

${ }^{17}$ Положение о межведомственной комиссии по вопросам охраны озера Байкал (утв приказом МПР России от 25.04.2007 № 114; в ред. приказов МПР РФ от 11.04.2008 № 91, Минприроды РФ от 11.08.2011 № 674). 
что она является координационным органом, образованным в целях согласования действий заинтересованных федеральных органов исполнительной власти, органов исполнительной власти Республики Бурятия, Иркутской области и Забайкальского края, по реализации государственной политики охраны озера Байкал.

В состав Комиссии входят представители Минприроды, Минэкономразвития, Минсельхоза, Минпромторга, Минэнерго, МИДа, МЧС России, Росгидромета, Ростехнадзора, Росприроднадзора, Росводресурсов, Рослесхоза, Роснедр, других министерств и ведомств, аппарата полномочного представителя Президента Российской Федерации в СФО, правительств Республики Бурятия, Иркутской области и Забайкальского края, Сибирского отделения РАН. Председателем Комиссии является министр природных ресурсов и экологии РФ.

Согласно Положению, объектами координации Комиссии является практически все, что связано с Байкалом и БПТ: социально-экономическое развитие, инвестиционная политика, природоохранное нормативно-правовое обеспечение на федеральном и региональном уровнях, экологический мониторинг, разработка и реализация целевых программ и проектов, международное сотрудничество, научное и информационное обеспечение выполняемых работ. Комиссия достаточно представительна и компетентна, но у нее нет правового статуса для организации совместных действий субъектов Федерации, министерств и ведомств.

Межрегиональный и надведомственный орган управления (он может иметь разные названия) должен координировать и сводить воедино экологическую политику на территории, осуществляемую профильными региональными департаментами, используя целевые программы и иные инструменты воздействия, включая региональные и муниципальные планы социально-экономического развития. Этот орган должен являться оператором федеральных целевых программ, связанных с Байкальской природной территорией. Возглавлять такой орган (или комитет) должен вице-премьер или другое должностное лицо, наделенное особыми надведомственными и надрегиональными полномочиями. Существующая Межведомственная комиссия может сохраниться как орган с консультативными, контрольными и арбитражными функциями, периодически рассматривая на своих заседаниях отдельные проблемы, по которым члены Комитета не смогли прийти к согласию.

Как шаг в создании интегрированной системы управления природоохранной деятельностью на Байкальской природной территории можно рассматривать тот факт, что 1 ноября 2017 г. приказом Генерального прокурора России создана Байкальская межрегиональная природоохранная прокуратура. Это вторая (после Волжской) природоохранная прокуратура, охватывающая несколько регионов. В ее состав войдут восемь межрайонных природоохранных прокуратур - в Братске, Иркутске, Усолье- Сибирское, Усть-Илимске и поселке Еланцы Ольхонского района Иркутской области, Улан-Удэ и Северобайкальске Бурятии, а также в Петровске-Забайкальском Забайкальского края. Основные задачи природоохранной прокуратуры - надзор за исполнением законов об охране окружающей среды и природопользовании, соблюдением прав граждан на благоприятную окружающую среду органами исполнительной власти всех уровней, коммерческими и некоммерческими организациями на территории регионов, расположенных в Байкало-Ангарском бассейне.

Проблема привлечения общественных сил, научного и образовательного потенциала на системной основе может решаться Межрегиональным комитетом через запросы инициативных проектов для решения определенных целей любого масштаба и значения на конкурсной основе. Такие запросы могут осуществляться и финансироваться также через федеральную целевую программу.

\section{Роль науки}

С 2002 г. в Иркутском научном центре работает (наиболее активно - до начала реформы РАН) Научный совет СО РАН по проблемам озера Байкал [Бычков и др., 2017]. Научная экспертиза законодательных и практических решений по охране озера Байкал и социально-экономическому развитию БПТ - основная функция Совета. В своей работе он взаимодействует с министерствами, Советом безопасности РФ, Федеральным собранием РФ, администрациями субъектов Федерации Байкальского региона. Совет фактически выступает основным органом научной экспертизы по байкальским вопросам, не имея другого официального статуса, кроме статуса Научного совета Сибирского отделения РАН. Правовой статус Научного совета целесообразно повысить, включив 
его в экспертную систему Российской академии наук с функциями выполнения научных экспертиз по поручению надведомственного органа (комитета) и Межведомственной комиссии по вопросам охраны озера Байкал.

Проблемы сохранения экосистемы Байкала не могут решаться без научного обоснования. Так, реализация программ устойчивого развития БПТ выдвигает в числе важнейших задач поиск и внедрение необходимых для экономики Байкальского региона новых технологий и «зеленых» производств, оказывающих наименьшее негативное либо даже позитивное влияние на окружающую среду. К ним, например, относятся создание биоэнергетических плантаций и использование тепловых насосов для теплоснабжения в зимний период за счет перепада температур вод Байкала и наружного воздуха. Целесообразны формирование некоторого «банка» возможных позитивных для Байкала технологий и проведение для них детальной технико-экономической оценки. Системная оценка эффективности внедрения новых технологий не только будет способствовать социальноэкономическому развитию региона, но и поможет в выработке обоснованных предложений для корректировки федерального законодательства, в частности, по видам деятельности, запрещенным в центральной экономической зоне БПТ. Это законодательство нуждается в научном обосновании, системной проработке и смягчении по многим позициям.

Перечень байкальских проблем известен ученым, властным структурам и общественности [Кузьмин и др., 2016]. Ученые не только Байкальского, но и других регионов России, нередко с участием иностранных коллег, многие десятилетия ведут исследования Байкала и БПТ. Многие научные проблемы Байкала требуют специальных многолетних исследований, для осуществления которых необходимо стабильное финансирование на систематической долгосрочной основе.

Велика роль науки в выработке объективного взгляда на процессы, происходящие на Байкальской природной территории. К сожалению, нередко в средствах массовой информации, даже в выступлениях некоторых научных работников, сильно преувеличивается масштаб негативных явлений, возникающих на Байкале. А отсутствие достоверной, научно доказанной информации о происходящих в Байкале процессах компенсируется сенсационными псевдонаучными «открытиями». Неверные оценки воздействия человека на природные комплексы ведут либо к беспечности в отношении последующих результатов, либо к неоправданному увеличению запретов, сдерживающих возможности экономического развития территории.

Например, с 1980-х годов существовало предубеждение, особенно за рубежом, да и у нас в стране, что Байкал весь отравлен стоками ЦБК. Конечно, это не соответствовало действительности - Байкал велик (сопоставим по площади, например, с Бельгией), и негативное влияние БЦБК имело локальный характер. В 2011 г. Лимнологическим институтом СО РАН была обнаружена несвойственная Байкалу водоросль спирогира [Тимошкин и др., 2014], которая в течение ряда лет расширяла пространство своего присутствия. Пока еще не ясны причины, прогноз дальнейшего развития этого явления. Не ясны также его последствия. Вместе с тем в некоторых «документальных» фильмах уже сообщается о том, что спирогира покрывает все побережье озера, и что это является огромным экологическим бедствием. Хотя для таких сенсационных заявлений нет оснований.

Следующий пример. По оценкам некоторых экспертов, численность байкальского омуля сократилась за последнее десятилетие вдвое. Это побудило к принятию срочных правительственных мер по запрещению лова омуля. Другие же эксперты считают, что сокращение если и произошло, то только на 20\%, что не выходит за рамки погрешностей используемых способов измерения численности омуля. На базе такой ненадежной основы было принято решение о запрете на лов омуля в Байкале, лишившее многих людей нередко единственного заработка. Логичнее было ожидать принятие правительственного решения, направленного на более углубленное изучение экосистемы озера, в том числе проблем рыбного хозяйства Байкала.

Много «шума», в том числе на центральном телевидении, произвела обнаружившаяся осенью 2017 г. гибель нескольких десятков нерп на юге Байкала. Один из авторов этой статьи в начале ноября 2017 г. участвовал в экспедиции на Байкале Лимнологического института СО РАН, в процессе которой были осмотрены все берега западной части озера от устья Ангары до острова Ольхон и все побережье острова. Ни одной погибшей нерпы на берегах не было обнаружено. Некоторые специалисты 
связывают отмечавшиеся факты ее гибели с чрезмерным возрастанием численности особей. Из экологических соображений уже много лет назад была запрещена охота на нерпу, и ее поголовье на Байкале возросло до 120-130 тыс. особей, что, по оценкам специалистов, на 20-30\% превышает оптимальное.

Bce это показывает, как много еще неизвестного в механизмах функционирования экосистемы озера Байкал. Наука должна стать равноправным партнером в стратегическом планировании и управлении экологическим и социально-экономическим развитием Байкальской природной территории.

\section{Литература}

Бычков И. В., Максимова И. И., Кузнецова А.Н. Власть и наука. Комментарии к отчету Научного совета СО РАН по проблемам озера Байкал // Вестник Российской академии наук. 2017. Т. 87. № 1. С. 27-38.

Грачев М.А. О современном состоянии экологической системы озера Байкал. Новосибирск: Издательство СО РАН, 2002. 156 с.

Кузьмин М.И., Буднев Н.М., Зверева Ю.М., Кузнецова А.Н. и др. Озеро Байкал // Вестник РФФИ. 2016. Спец. выпуск № 1. 108 с.

Суходолов А. П. Быть ли городу на Байкале? Новосибирск: Наука, 1996. $248 \mathrm{c}$.

Тимошкин О.А., Мальник В.В., Сакирко М. В., Боедекер К. Экологический кризис на Байкале: ученые ставят диагноз // Наука из первых рук. 2014. Т. 59. № 5. C. $75-91$.

Albert M.T., Richon N., Vinals M.J., Whitecomb A. (eds). 2012. Community Development through World Heritage. Paris, UNESCO World Heritage Centre. World Haritage Papers No. 31

GLRI Projects. [Эл. pecypc]. URL: https://www.glri.us/projects/. (дата обращения: 01.03.2018).

Great Lakes Restoration Initiative Action Plan. 2/21/2010. [Эл. pecypc]. URL: https://www.dec.ny.gov/docs/regions_pdf/glriplan.pdf. (дата обращения 15.08.2017).

Great Lakes Restoration Initiative Action Plan II. September, 2014. [Эл. pecypc] URL: https://www.glri.us/actionplan/pdfs/glri-action-plan-2.pdf. (дата обращения: 15.08.2017).

Evaluation of the Great Lakes Program. Final Report. Audit and Evaluation Branch. March 2017. Environment and Climate Change Canada. [Эл. pecypc]. URL: https://www.canada.ca/content/dam/eccc/documents/pdf/ evaluation-greatlake-program/Evaluation of the great_Lakes program.pdf (дата обращения: 15.08.2017).

Статья поступила 14.12.2017.

\section{Summary}

V.I. Zorkaltsev, Melentiev Energy Systems Institute Siberian Branch of the Russian Academy of Sciences, Irkutsk Scientific Center of Siberian Brunch of the Russian Academy of Science, A.N. Kuznetsova, Irkutsk Scientific Center of Siberian Brunch of the Russian Academy of Science, N.M. Sysoeva, Irkutsk Scientific Center of Siberian Brunch of the Russian Academy of Science, V.B.Sochava Institute of Geography of Siberian Brunch of the Russian Academy of Science, Irkutsk State University

\section{Ecological problems of the Lake Baikal}

Ecological problems of the Baikal natural territory, the existing difficulties in their solution are considered. Many problems result from the territorial and departmental disunity of the authorities involved in the development of the Baikal natural territory. The possibility of using the experience of the revival of the Great Lakes of North America is discussed. Particular attention is paid to the need to develop scientific researches of Bakal.

Ecological problems; Baikal natural territory; ecosystem of Lake Baikal

\section{References}

Bychkov I. V., Maksimova I. I., Kuznetsova A. N. (2017). Vlast' i nauka. Kommentarii k otchetu Nauchnogo soveta SO RAN po problemam ozera Bajkal. Vestnik Rossijskoj akademii nauk. [Herald of the Russian Academy of Sciences]. T. 87. No 1. Pp. 27-38. (In Russ).

Grachev M.A. (2002). O sovremennom sostoyanii ehkologicheskoj sistemy ozera Bajkal. Novosibirsk: Izdatel'stvo SO RAN Publ. 156 p. (In Russ).

Kuz'min M.I., Budnev N.M., Zvereva Ju.M., Kuznetsova A.N. i dr. (2016) Ozero Bajkal. Vestnik RFFI. [RFBR Journal]. Spec. vypusk No 1. 108 p. (In Russ).

Suhodolov A.P. (1996). Byt' li gorodu na Bajkale? Novosibirsk, Nauka Publ. 248 p. (In Russ).

Timoshkin O.A., Mal'nik V.V., Sakirko M.V., Boedeker K. (2014). Ehkologicheskij krizis na Bajkale: uchenye stavyat diagnoz. Nauka iz pervyh ruk. [Science First Hand]. T. 59. № 5. Pp. 75-91. (In Russ).

Albert M. T., Richon N., Vinals M.J., Whitecomb A. (eds). (2012). Community Development through World Heritage. Paris, UNESCO World Heritage Centre. World Haritage Papers No. 31.

GLRI Projects. Available at: https://www.glri.us/projects/. (accessed 01.03.2018). Great Lakes Restoration Initiative Action Plan. 2/21/2010. Available at: https:// www.dec.ny.gov/docs/regions_pdf/glriplan.pdf. (accessed 15.08.2017).

Great Lakes Restoration Initiative Action Plan II. September, 2014. Available at: https://www.glri.us/actionplan/pdfs/glri-action-plan-2.pdf. (accessed 15.08.2017).

Evaluation of the Great Lakes Program. Final Report. Audit and Evaluation Branch. March 2017. Environment and Climate Change Canada. Available at: https:// www.canada.ca/content/dam/eccc/documents/pdf/evaluation-great-lake-program/ Evaluation_of_the_great_Lakes_program.pdf. (accessed 15.08.2017). 